\title{
CMALT and CMOOC - a community of educators and their learning technologies
}

\author{
Lisa Ransom \\ Auckland University of Technology \\ lisa.ransom@aut.ac.nz
}

Submission Type: Brief Presentation (20mins + 10minsQ\&A)

Keywords: CMALT, SoTL, SoTEL

\section{Abstract:}

CMALT - Certified Member of the Association for Learning Technology - is a peer-reviewed accreditation based upon the UKPSF (UK Professional Standards Framework) - https://www.alt.ac.uk/certified-membership. This enables staff (whether academic or administrative) who embed learning technologies in either their teaching or support roles, to showcase their experiences and gain recognition. This programme has been developed by ALT and is co-delivered online, by ASCILITE.

Building upon the experiences of supporting a geographically distributed project involving six institutions nationally across New Zealand during 2014-2015, we (AUT) have developed a support structure for building communities around CMALT accreditation using a cMOOC model. The cMOOC framework enables us to bridge and broker authentic participation within an international community of academics and learning technologists interested in exploring CMALT accreditation, and we have had participation from the UK, Japan, Canada, Australia, and NZ. The CMALT cMOOC was developed in 2017 by the Centre for Learning and Teaching, at Auckland University of Technology, and endorsed by ALT and ASCILITE in 2019.

This presentation will highlight the ecology of resources that are used to support the community and hear from current participants of the programme. 